\title{
GERMINAÇÃO DE EMBRIÕES E MULTIPLICAÇÃO IN VITRO DE ETLINGERA ELATIOR (JACK) R.M. SMITH
}

\author{
Jaqueline Figueredo de Oliveira ${ }^{1 *}$, Eurico Eduardo Pinto de Lemos $^{1}$, Leila de Paula Rezende ${ }^{1}$, Vilma Marques
}

Ferreira ${ }^{1}$, Denis Medeiros dos Santos ${ }^{2}$, Míria de Lima Holanda ${ }^{3}$

\author{
${ }^{1}$ Centro de Ciências Agrárias, Universidade Federal de Alagoas, BR 104 Norte, Km 85, Rio Largo, AL. \\ ${ }^{2}$ Empresa Brasileira de Agropecuária Tabuleiros Costeiros, BR 104 Norte, Km 85, Rio Largo, AL. \\ ${ }^{3}$ Instituto de Ciências Biológica e da Saúde, Universidade Federal de Alagoas, Av. Lourival Melo Mota, s/n, Tabuleiro do \\ Martins, Maceió, AL. \\ “Autor para corespondência: Jaqueline Figueredo de Oliveira, jaquelinefigueredo@hotmail.com
}

RESUMO - Etlingera elatior(Jack) R.M. Smith é uma planta tropical florífera. O objetivo do trabalho era desenvolver um protocolo para multiplicação in vitro de Etlingera elatior, onde foram testados os efeitos da adição da citocinina 6-benzilaminopurina (BAP) em meio de cultura de Murashige e Skoog na germinação de embriões in vitro. Foram ainda estudados os efeitos da adição das citocininas (BAP) e cinetina (CIN) e da auxina ácido naftaleno acético na multiplicação in vitro dos explantes. As plântulas com cerca de $2 \mathrm{~cm}$ foram cultivadas no meio de cultura (MS), enriquecido com $1 \mathrm{mg} \mathrm{L-1} \mathrm{BAP} \mathrm{mais} \mathrm{um} \mathrm{dos} \mathrm{seguintes} \mathrm{tratamentos:} \mathrm{1)} 1 \mathrm{mg} \mathrm{L}{ }^{-1}$ ANA (Ácido naftalenoacético); 2) 2 $\left.\mathrm{mg} \mathrm{L}^{-1} \mathrm{ANA} 3\right) 1 \mathrm{mg} \mathrm{L}^{-1} \mathrm{CIN}$; 4) $2 \mathrm{mg} \mathrm{L}^{-1} \mathrm{CIN}$. Os resultados mostraram que houve maior percentagem de formação de calos (30\%) em embriões excisados quando transferidos em meio de cultura com $2 \mathrm{mg} \mathrm{L}^{-1}$ de BAP. Após 90 dias de cultivo, o maior número médio de brotos $(4,4)$ foi obtido com $1 \mathrm{mg} \mathrm{L}^{-1} \mathrm{BAP}+2 \mathrm{mg} \mathrm{L}^{-1} \mathrm{CIN}$ e a maior altura média dos brotos foram obtidas na concentração de $1 \mathrm{mg} \mathrm{L}^{-1} \mathrm{BAP}+2 \mathrm{mg} \mathrm{L}^{-1} \mathrm{ANA}$. O maior número e comprimento médio das raízes foram obtidos com $1 \mathrm{mg} \mathrm{L}^{-1} \mathrm{BAP}+2 \mathrm{mg} \mathrm{L}^{-1} \mathrm{ANA}$. A taxa de pegamento das plântulas foi superior a $80 \%$, as quais estavam prontas para serem transferidas para o campo aos 60 dias.

Palavras-chave: cultura de tecidos, Zingiberaceae, embriogênese.

\section{THE GERMINATION OF ZIGOTIC EMBRYOS AND MICROPROPAGATION OF ETLINGERA ELATIOR (JACK) R.M. SMITH}

\begin{abstract}
Etlingera elatior (Jack) R.M. Smith is an ornamental tropical plant. The objective of the work was to develop a protocol for multiplication in vitro of Etlingera elatior, where it was tested the effects of the addition of the citocinina 6-benzilaminopurina (BAP) in middle of culture of Murashige and Skoog (BAD) in the germination of embryos in vitro. They were still studied the effects of the addition of the citocininas (BAP) and cinetina (CIN) and of the auxina acid acetic naftaleno in the multiplication in vitro of the explantes. The plântulas individualized with about $2 \mathrm{~cm}$ they were cultivated in the middle of culture (BAD), enriched with $1 \mathrm{mg}$.L-1 BAP one more of the following treatments: 1) $1 \mathrm{mg} \mathrm{L-1}$ ANA (Acid naftalenoacético); 2) 2 mg L-1 ANA 3)1 mg L-1 CIN; 4) 2 mg L-1 CIN. The results showed that there was larger percentage of formation of calluses (30\%) in embryos excisados when put in middle of culture with $2 \mathrm{mg} \mathrm{L}-1$ of BAP. After 90 days of cultivation, the largest medium number of sprouts $(4,4)$ it was obtained with $1 \mathrm{mg} \mathrm{L}-1 \mathrm{BAP}+2 \mathrm{mg}$ $\mathrm{L}-1 \mathrm{CIN}$ and the largest medium height of the sprouts they were obtained in the concentration of $1 \mathrm{mg} L-1 \mathrm{BAP}+2 \mathrm{mg}$ L-1 ANA. The largest number and medium length of the roots were obtained with $1 \mathrm{mg}$ L-1 BAP+2 mg L-1 ANA. The rate of recovering the plantlets was superior to $80 \%$ that were ready for they are transferred for the field to the 60 days.
\end{abstract}

Index terms: tissue culture, zingiberaceae, embriogênese.

\section{INTRODUÇÃO}

0 mercado mundial de flores vem apresentando crescimento significativo a partir da década de 90, tornando-se um segmento econômico de grande importância no agronegócio global com um valor aproximado de três bilhões de dólares anuais dos quais consideráveis parcelas se deve à comercialização de espécies de origem tropical (Loges et al., 2003). 
No Brasil, a produção de flores tropicais tem crescido significativamente, especialmente na região Nordeste. Nesta região, pequenos e médios produtores possuem vantagens competitivas devido às condições ambientais ideais para o cultivo das mais belas espécies (Rodrigues, 2005).

Em Alagoas, as espécies de flores tropicais cultivadas pertencem principalmente às famílias Musaceae, Heliconiaceae e Zingiberaceae (Chagas, 2000; Castro, 1995). Entre as Zingiberaceae, destacase a espécie Etlingera elatior (Jack) R.M. Smith, denominada "bastão do imperador", com os tipos vermelho, rosa e porcelana. (Chagas, 2000).

Devido à sua beleza e a durabilidade na póscolheita, o bastão do imperador tem sido comercializado como flor de corte, com grande aceitação tanto no mercado nacional como internacional, sendo utilizada também em arranjos paisagísticos de jardins, praças e bosques (Castro, 1998).

Recentemente, diversas técnicas de biotecnologia têm sido utilizadas em trabalhos de melhoramento e clonagem de espécies de flores tropicais, podendo-se destacar a cultura de tecidos com suas técnicas de micropropagação e resgate de embriões de sementes em cruzamentos entre espécies incompatíveis (Duval, 2004; Rodrigues, 2005; Torres et al., 2005). Todavia, até o presente momento, não foram descritos trabalhos enfocando experiências em cultura de tecidos com a espécie Etlingera elatior.

As mudas de bastão do imperador são obtidas vegetativamente pelo processo de divisão de touceiras ou por seccionamento de rizomas (Lamas, 2002). Tais métodos de propagação além de restringirem o número de mudas disponíveis para novos produtores podem ocasionar a disseminação de pragas e doenças, levando ao acúmulo de agentes patogênicos que são transmitidos entre plantios sucessivos. Para resolver esse problema, tem sido sugerida a utilização da técnica de cultura de meristemas e outros tecidos das plantas, entre os quais estão os embriões zigóticos obtidos de sementes antes ou após a sua maturação. Esta técnica tem mostrado ser uma forma rápida de multiplicar uma determinada espécie autógama com características agronômicas desejáveis, recuperando plantas livres de pragas e doenças e já tem se mostrado uma opção viável para algumas espécies da família Zingiberaceae (Mello et al., 2000; Willadino \& Câmara, 2006).
0 objetivo desse trabalho foi desenvolver um protocolo de regeneração de plantas de Etlingera elatior cv. Red Torch, através do cultivo de embriões maduros e avaliar a multiplicação e enraizamento in vitro dos explantes sob diferentes concentrações das citocininas 6-benzilaminopurina e cinetina e da auxina ácido naftaleno acético como opção para utilização em sistemas de propagação massal, visando à produção de plantas livres de pragas e doenças.

\section{MATERIAL E MÉTODOS}

O trabalho foi conduzido no Laboratório de Biotecnologia Vegetal do Centro de Ciências Agrárias da Universidade Federal de Alagoas, em Rio Largo Estado de Alagoas.

\section{Obtenção das sementes}

Frutos maduros de Etlingera elatiorcv. Red Torch, provenientes de plantio comercial na Fazenda Monteiro no município de Messias, Alagoas, foram mergulhados em solução de hipoclorito de sódio a 0,2\% por 30 minutos e em seguida lavados com água corrente por 1 minuto. As sementes foram retiradas dos frutos e despolpadas em uma peneira, sob água corrente, até a retirada total da mucilagem. Em câmara de fluxo laminar, foi realizada a desinfestação de acordo com a sequencia: 1) Imersão em $1 \mathrm{~L}$ de água destilada com 3 gotas de detergente comum por 10 minutos; 2) Imersão por 10 minutos em fungicida tiofanato metílico (Cercobim $700 \mathrm{PM}$ ) a $2 \mathrm{~g} \mathrm{~L}^{-1}$; 3) Imersão por 1 minuto em álcool 70\% (v/v); 4) Imersão por 30 minutos em solução de hipoclorito de sódio a $0,6 \%$, juntamente com 2 gotas do detergente Tween 80 . Ao final de cada etapa, as sementes receberam três enxágües em água estéril.

\section{Germinação de embriões zigóticos isolados}

Sementes de Etlingera elatior cv. Red Torch foram utilizadas para extração dos embriões, com auxílio de microscópio estereoscópico, os quais foram introduzidos em tubos-de-ensaio contendo $10 \mathrm{~mL}$ de meio de culturaMS (Murashigee Skoog, 1962) acrescido de $30 \mathrm{mg} \mathrm{L}^{-1}$ de sacarose, e diferentes concentrações de $\operatorname{BAP}\left(0 ; 1 ; 2\right.$ e $\left.3 \mathrm{mg} \mathrm{L}^{-1}\right)$, com pH ajustado para 5,8 e gelificado com 2,5 g.L-1 de "Phytagel", autoclavado por 20 minutos, a $121^{\circ} \mathrm{C}$. Os embriões foram cultivados no escuro por 15 dias e após este tempo foram mantidos em sala de crescimento, sob intensidade luminosa de 
cerca de $50 \mathrm{mmol} \cdot \mathrm{m}^{-2} \cdot \mathrm{s}^{-1}$. O fotoperiodo foi de 16 horas a $25+-2^{\circ} \mathrm{C}$. Após 60 dias de cultivo, os embriões isolados que germinaram e se desenvolveram foram transferidos para o mesmo meio de cultura MS sem reguladores de crescimento, e mantidos em sala de crescimento nas mesmas condições. $O$ experimento foi organizado em delineamento experimental inteiramente casualizado, com 5 repetições e 4 embriões por parcela. Durante 60 dias, foi avaliado a por percentuagem de germinação de embriões e a presença de calos a cada 15 dias

\section{Germinação de sementes in vitro}

Sementes de Etlingera elatior cv. Red Torch foram germinadas em papel de filtro umedecido dentro de placas de Petri esterilizadas em autoclave. Este ensaio foi constituído de 10 placas cada uma contendo 10 sementes. Após 60 dias avaliou-se a porcentagem de germinação das sementes. As sementes germinadas nas placas foram transferidas para frascos contendo $30 \mathrm{~mL}$ do meio de cultura MS, utilizado anteriormente para os embriões, suplementado com $3 \mathrm{mg} \mathrm{L}^{-1}$ de BAP. A cada 30 dias, os explantes eram repicados até a obtenção de uma quantidade suficiente para o início do experimento de multiplicação.

\section{Experimento de multiplicação}

As plântulas individualizadas com cerca de $2 \mathrm{~cm}$, foram cultivadas no meio de cultura MS, suplemetado com $30 \mathrm{~g} \mathrm{~L}^{-1}$ de sacarose e $1 \mathrm{mg} \mathrm{L}^{-1}$ BAP mais um dos seguintes tratamentos: 1) $1 \mathrm{mg} \mathrm{L}^{-1} \mathrm{ANA}$ (Ácido naftalenoacético); 2) $2 \mathrm{mg} \mathrm{L}^{-1}$ ANA 3) $1 \mathrm{mg} \mathrm{L}^{-1} \mathrm{CIN}$ (Cinetina); 4) $2 \mathrm{mg} \mathrm{L}^{-1} \mathrm{CIN}$. As avaliações foram feitas quinzenalmente por 90 dias, contando-se o número de brotos e de raízes por explantes e medindo-se 0 comprimento dos mesmos. As variáveis comprimento de brotos e de raiz foram medidas com ajuda de uma régua. Os explantes foram transferidos para meio novo a cada 30 dias. Os experimentos foram conduzidos em delineamento experimental inteiramente casualizado com 4 tratamentos e 5 repetições, sendo cada parcela representada por frascos com uma planta cada. Utilizouse frascos $(250 \mathrm{ml})$ contendo cerca de $30 \mathrm{~mL}$ de meio. Os dados foram submetidos à análise de variância $e$ as médias dos tratamentos foram comparadas pelo teste de Tukey a $5 \%$ de probabilidade. Foi utilizado 0 programa estatístico SISVAR-Sistema de análise de variância para dados balanceados. Todas as fases do presente estudo, com exceção dos primeiros 15 dias da fase escura dos embriões isolados, foram conduzidas em câmara de crescimento sob intensidade luminosa de cerca de $50 \mathrm{mmol} \cdot \mathrm{m}^{-2} \cdot \mathrm{s}^{-1}$, proveniente de lâmpadas frias Philips TDL. 0 fotoperíodo utilizado de 16 horas e à temperatura foi ajustada para $25^{\circ} \mathrm{C}$.

Paraaaclimatização domaterial, foram selecionadas microplantas, com cerca de $3 \mathrm{~cm}$, enraizadas in vitro, as quais tiveram suas raízes lavadas em água corrente para a completa remoção do meio de cultura aderido. Em seguida foram transplantadas em copos descartáveis com capacidade para $200 \mathrm{~mL}$, contendo uma mistura de pó de fibra de coco, terra de encosta e torta de filtro nas proporções de 1:2:1. Os copos com as plantas foram mantidos em bandejas envolvidas com sacolas plásticas durante 15 dias para formar uma câmara úmida. Após esse período, os copos com as plântulas foram levados para um telado com $70 \%$ de sombreamento e irrigados diariamente por microaspersão. Após 30 dias da retirada das plantas dos frascos, avaliou-se a porcentagem de plantas vivas e a altura das plantas.

\section{RESULTADOS E DISCUSSÃO}

\section{Germinação de embriões zigóticos isolados}

$O$ início da germinação dos embriões ocorreu aos 15 dias para os tratamentos com até $2 \mathrm{mg}^{\mathrm{L} \mathrm{L}^{-1}}$ de BAP. $\mathrm{O}$ temponecessário paraagerminaçãomáximadosembriões foi de 30 dias, não havendo embriões germinados após esse período em todos os tratamentos. Após 15 dias de introdução in vitro dos embriões, observou-se a formação de um calo esbranquiçado de consistência esponjosa ao longo do eixo de todos embriões que germinaram. A presença dos calos nos embriões pode esta associada estar associada, ao crescimento dos mesmos uma vez que os embriões que não germinaram não apresentaram nenhum tipo de resposta morfogênica ou qualquer tipo de calo na superfície.

Duval (2004), cultivando embriões de Heliconia rostrata em meio básico de MS observou que a ausência de reguladores de crescimento juntamente com a adição de sacarose foram fundamentais para a germinação dos embriões. Contrariamente, nesse trabalho, a adição de BAP até a concentração de $2 \mathrm{mg} \mathrm{L}^{-1} \mathrm{em}$ meio com 3\% de sacarose, favoreceu a germinação dos embriões de Etlingera elatior em relação à testemunha sem BAP. Todavia, o aumento da concentração de BAP para $3 \mathrm{mg} \cdot \mathrm{L}^{-1}$ no mesmo meio básico desfavoreceu a germinação dos embriões (Figura 1). 


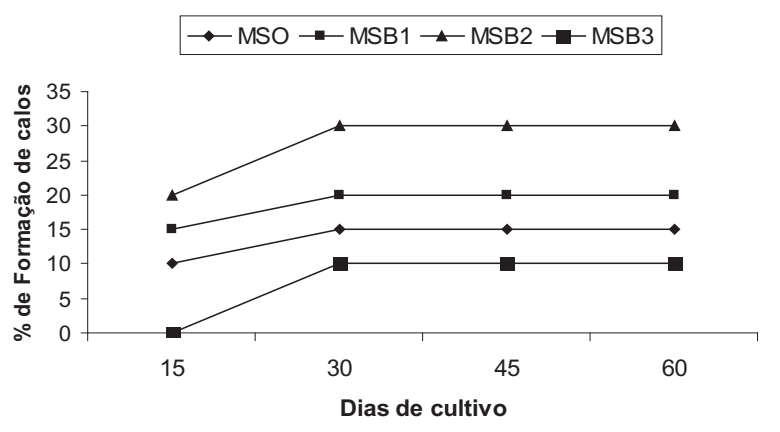

FIGURA 1: Efeito das diferentes concentrações de BAP $\left(0,1,2\right.$ e $\left.3 \mathrm{mg}^{\mathrm{L}} \mathrm{L}^{-1}\right)$ de BAP, na formação de calos isolados de Etlingera elatior cv. Red Torch, aos 60 dias de cultivo in vitro.

A baixa porcentagem de germinação dos embriões pode ser devido ao estágio de maturação da semente que no caso de Etlingera elatior carece de maiores estudos. De acordo com Hu \& Ferreira (1998), quanto mais jovens os embriões, mais difícil é o cultivo in vitro, devido ao seu pequeno tamanho e danos durante a excisão e, mais complexos são suas exigências nutricionais. Rhaghavan (1980) descreve que embriões em fase inicial de desenvolvimento são heterotróficos e, muitas vezes, as condições ideais de nutrição são desconhecidas.

Aos 45 dias após a inoculação dos embriões isolados observou-se distintamente o crescimento da raiz e da parte aérea nos tratamentos com até $2 \mathrm{mg} \mathrm{L}^{-1}$ de BAP (Figura 2 $\mathrm{A}, \mathrm{B}, \mathrm{C})$. No meio suplementado com $3 \mathrm{mg} \mathrm{L}^{-1}$ de BAP (Figura 2 D) houve crescimento da massa esponjosa esbranquiçada (calos) até os 60 dias, após este período iniciou-se o escurecimento e posteriormente morte do calo e do embrião, 0 que não ocorreu com os demais tratamentos que embora tenham produzido diferentes quantidades de calo não levaram os embriões à morte.

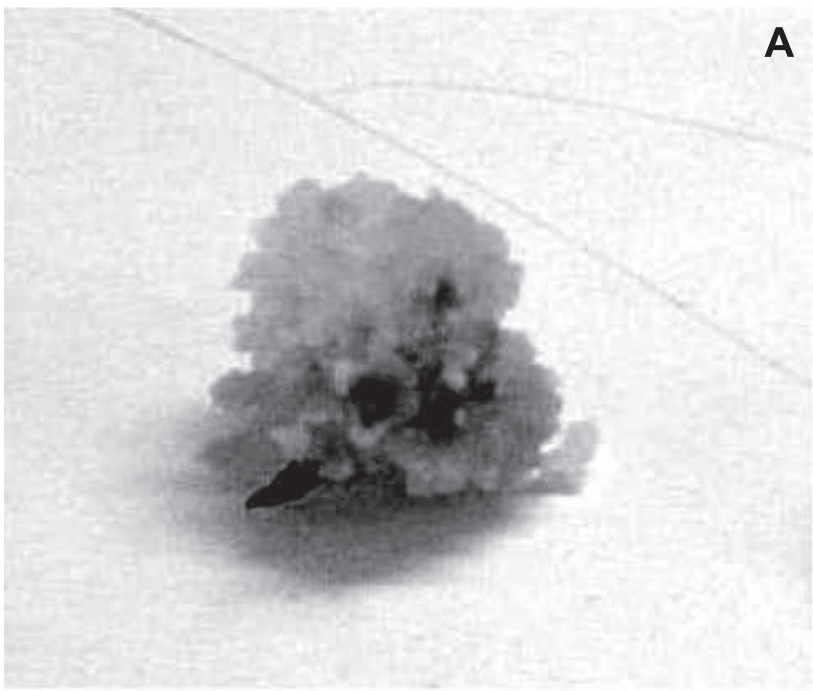

A
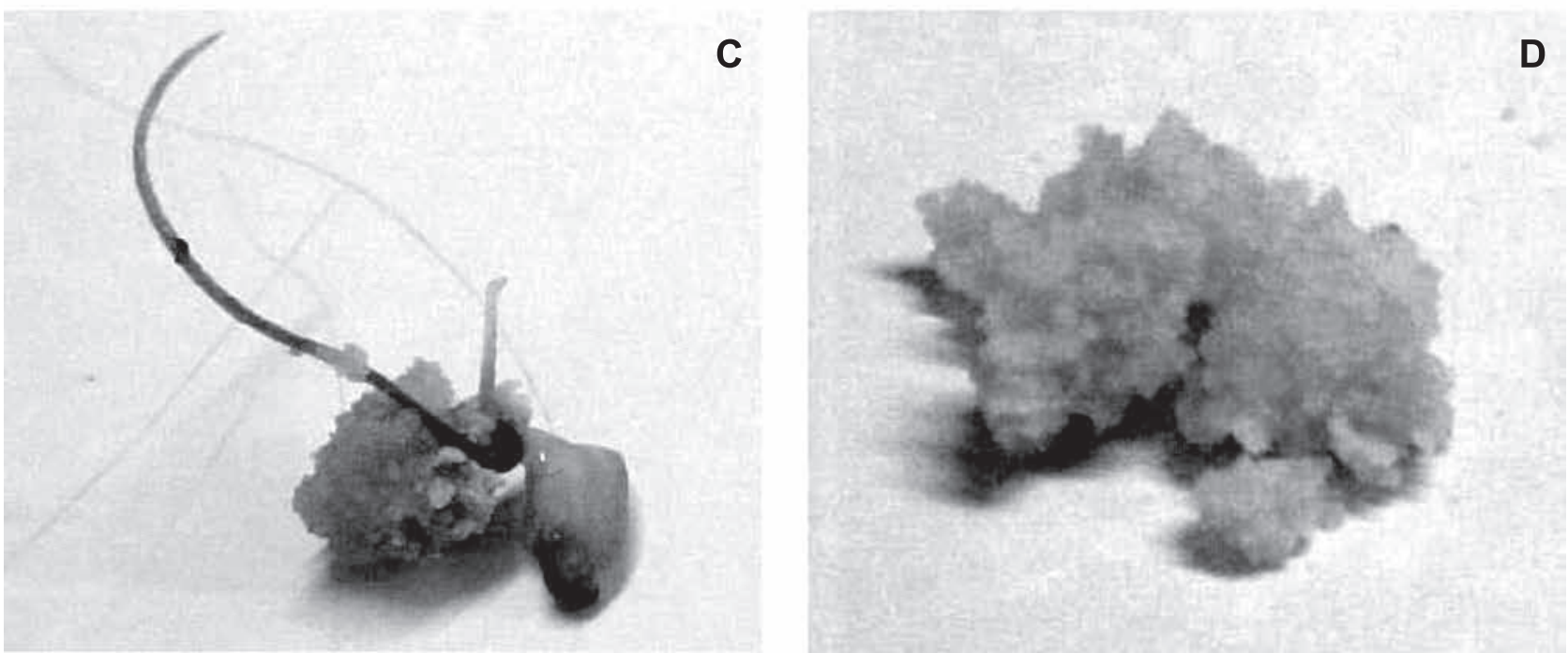

FIGURA 2. Embriões em desenvolvimento com estrutura calosa esbranquiçada, parte aérea e raiz, provenientes de meio MS, suplementado com $0 \mathrm{mg} \cdot \mathrm{L}^{-1}(\mathrm{~A}), 1 \mathrm{mg} \cdot \mathrm{LL}^{-1}(\mathrm{~B}), 2 \mathrm{mg} \cdot \mathrm{L}^{-1}(\mathrm{C})$ e $3 \mathrm{mg} \cdot \mathrm{L}^{-1}(\mathrm{D})$. 
A resposta de tecidos vegetais à produção de calos pode ocorrer de diversas maneiras, sendo estimulada ou não pela presença de reguladores de crescimento como auxinas e citocininas (George, 1993). Nesse caso, o simples fato dos embriões retornarem 0 crescimento do eixo embrionário estimulou também a formação de calos independentemente do meio conter ou não a presença de BAP. É possível que o isolamento de embriões tenha desencadeado um descontrole morfogenético do crescimento na superfície do eixo embrionário no contato com o meio rico em nutrientes sem prejuízo para o crescimento dos meristemas da parte aérea e da raiz. A osmolaridade do meio também influencia o desenvolvimento de embriões isolados e, é possível que, neste caso, a mesma necessitasse de ajustes (Hu \& Ferreira, 1998).

\section{Germinação de sementes in vitro}

A introdução in vitro das sementes de Etlingera elatior, em placas de Petri, proporcionou a obtenção de explantes viáveis. A taxa de germinação das sementes foi de apenas $8 \%$, aos 60 dias após a introdução. Essa taxa foi significativamente menor do que aquelas obtidas com embriões retirados das sementes e foram germinados em meio de cultura MS, com e sem BAP, que atingiram até $30 \%$ em $2 \mathrm{mg} \mathrm{L}^{-1}$ de BAP. Esse fato pode estar relacionado à possibilidade das sementes apresentarem dormência física, pois quando maduras, elas possuem um tegumento bastante duro e impermeável. Outra possibilidade seria a presença, ainda não confirmada, de inibidores de germinação nos tecidos que revestem o embrião da semente conforme constatado em várias espécies (Hu \& Ferreira, 1998).

\section{Experimento de multiplicação}

Os tratamentos apresentaram diferenças significativas em resposta às diferentes concentrações de reguladores de crescimento testadas. 0 maior número de brotações $(4,4)$ foi obtido quando se adicionou $1 \mathrm{mg} \mathrm{L}^{-1}$ de BAP $+2 \mathrm{mg} \mathrm{L}^{-1}$ de $\mathrm{CIN}$ no meio (Tabela 1). Trabalhos publicados, sobre a micropropagação de plantas da família Zingiberaceae mostram que o meio de cultura MS, tem sido o mais utilizado para a multiplicação in vitro. A associação de reguladores de crescimento tem sido também utilizada como estratégia para o crescimento e multiplicação. Por exemplo, Loc et al. (2005), utilizando várias combinações de reguladores de crescimento na multiplicação de Curcuma zedoaria Roscoe, obtiveram o melhor número médio de brotações/mês $(5,6)$ ao utilizar o meio de cultura MS acrescido de $3 \mathrm{mg} \mathrm{L}^{-1}$ de BAP associado a $0,5 \mathrm{mg} \mathrm{L}^{-1}$ de IBA. Borthakur et al. (1999), utilizando o meio de cultura MS suplementado com $3 \mathrm{mg} \mathrm{L}^{-1}$ de CIN para a multiplicação in vitro de Alpinia galanga obtiveram um número médio de 7,1 brotos/mês. No entanto quando utilizaram $4 \mathrm{mg} \mathrm{L}^{-1}$ de $\mathrm{CIN}+0,5 \mathrm{mg} \mathrm{L}^{-1}$ de ANA houve uma redução no número médio de brotos/mês para 5.

TABELA 1: Efeito da adição de reguladores de crescimento no número e comprimento médio das brotações $(\mathrm{cm})$ e na taxa de multiplicação de Etlingera elatior cv. Red Torch, aos 90 dias de cultivo in vitro.

\begin{tabular}{cccc}
\hline Tratamentos & Número das brotações & Comprimento das brotações $\mathbf{( c m})$ & Taxa de multiplicação* \\
\hline $1 \mathrm{mg} / \mathrm{L} \mathrm{BAP}+1 \mathrm{mg} \cdot \mathrm{L}^{-1} \mathrm{ANA}$ & $3,6 \mathrm{c}$ & $2,51 \mathrm{a}$ & 8,12 \\
$1 \mathrm{mg} / \mathrm{L} \mathrm{BAP}+2 \mathrm{mg} \cdot \mathrm{L}^{-1} \mathrm{ANA}$ & $3,8 \mathrm{bc}$ & $2,60 \mathrm{a}$ & 7,84 \\
$1 \mathrm{mg} / \mathrm{L} \mathrm{BAP}+1 \mathrm{mg} \cdot \mathrm{L}^{-1} \mathrm{CIN}$ & $4,1 \mathrm{ab}$ & $2,32 \mathrm{~b}$ & 9,36 \\
$1 \mathrm{mg} / \mathrm{L} \mathrm{BAP}+2 \mathrm{mg} \cdot \mathrm{L}^{-1} \mathrm{CIN}$ & $4,4 \mathrm{a}$ & $2,31 \mathrm{~b}$ & 10,04 \\
\hline $\mathrm{CV}(\%)$ & 17,03 & 10,79 & \\
\hline
\end{tabular}

Médias seguidas de mesma letra nas colunas não diferem estatisticamente entre si pelo teste de Tukey (5\%). *Número final de explantes produzidos/ número de explantes introduzidos.

De acordo com Sharma \& Singer (1997), gemas de Zingiber officinalle cultivadas em meio de cultura MS suplementado com os reguladores de crescimento BAP, CIN, ANA e IBA, mostraram que a suplementação isolada do meio de cultura com $8 \mathrm{mg}$ $\mathrm{L}^{-1}$ de CIN induziu uma média de 4,3 novos brotos/mês e a suplementação combinada com $2 \mathrm{mg} \mathrm{L}^{-1}$ de $\mathrm{CIN}+$ $2 \mathrm{mg} \mathrm{L}^{-1}$ de ANA, induziu uma média de 7 brotos/mês.
A média de brotos/mês superior a 4 mostra que os resultados obtidos nesse trabalho se aproximam dos valores obtidos em outras espécies mais estudadas da mesma família.

O comprimento médio das brotações foi maior nos tratamentos combinados com a citocinina (BAP) e auxina (ANA). Portanto, a suplementação do meio MS com $1 \mathrm{mg} \mathrm{L}^{-1}$ BAP associado a $2 \mathrm{mg} \mathrm{L}^{-1}$ de ANA 
proporcionou maior comprimento médio das brotações $(2,6 \mathrm{~cm})$ (Tabela 1).

Hu \& Wang (1986), relatam que a auxina na multiplicação parece anular o efeito inibitório que as citocininas têm sobre 0 alongamento das culturas. Foi verificado, por exemplo, que nos meios de multiplicação de diversos clones de Eucalyptus, contendo citocinina, as partes aéreas se alongaram com a adição de AIA ou AIB. Com o mesmo objetivo, uma auxina pode ser utilizada para estimular o enraizamento do explante inicial ea manutenção de um caule único com dominância apical num sistema onde novos segmentos nodais sejam desejados como forma de multiplicação (Grattapaglia \& Machado, 1998).

$\mathrm{Na}$ figura $3 \mathrm{~A}$ observa-se 0 número médio das brotações em trêsépocas diferentes de cultivo in vitro $(30,60$ e 90 dias), mostrando diferenças estatísticas significativas entre as épocas em todos os tratamentos. Porém, após 90 dias de cultivo obteve-se a maior proliferação de brotos/ explantes para todos os tratamentos utilizados.
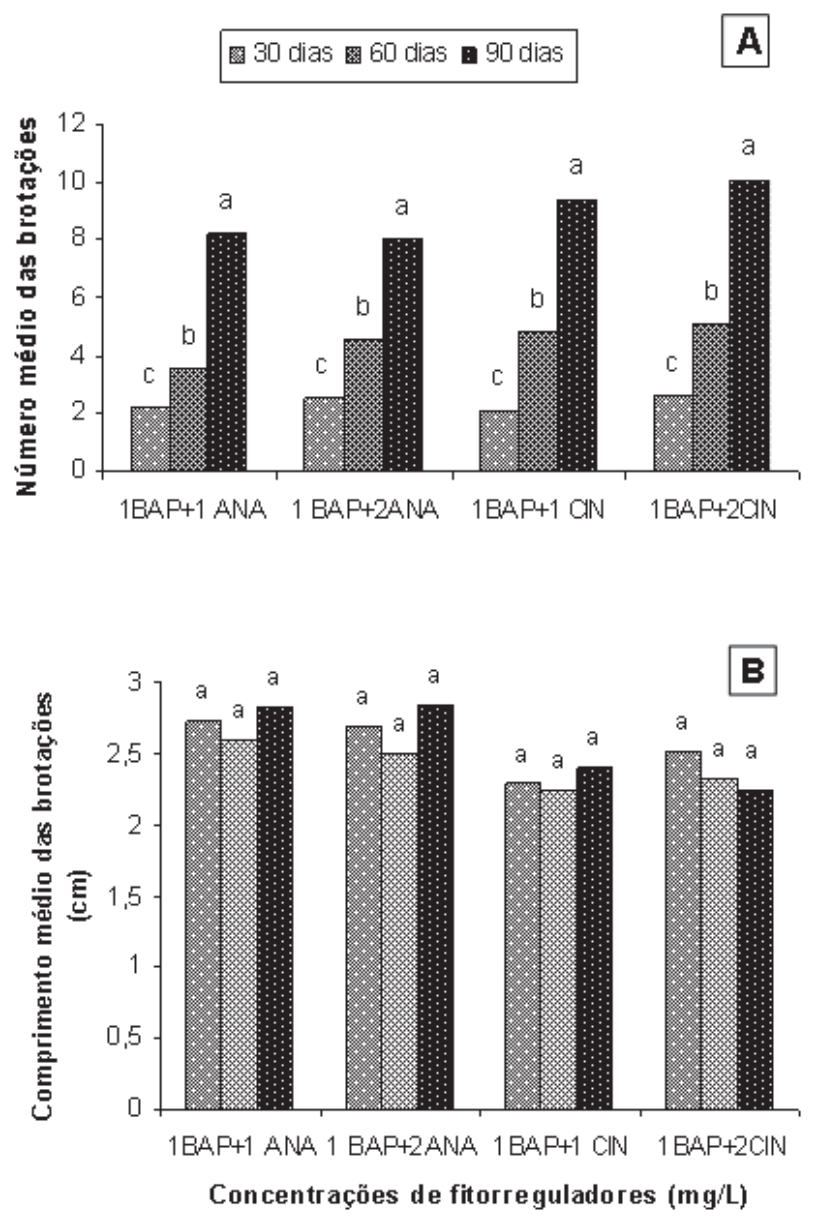

FIGURA 3: Número médio (A) e comprimento médio (B) das brotações de Etlingera elatior cv. Red Torch emitidos por explantes iniciais aos 30,60 e 90 dias de cultivo in vitro nos diferentes tratamentos. Médias seguidas da mesma letra não diferem estatisticamente pelo teste de Tukey (5\%).
O comprimento médio das brotações ao longo do tempo observado, não mostrou diferenças estatísticas entre as épocas (30, 60 e 90 dias) indicando que, o aumento do número médio das brotações, nos explantes, manteve o comprimento médio dos mesmos constante nas diferentes épocas (Figura 3B).

O número médio das raízes aumentou significativamente nos tratamentos combinados com citocinina (BAP) e auxina (ANA), sendo o tratamento que mais favoreceu ao enraizamento com $1 \mathrm{mg} \mathrm{L}^{-1}$ BAP $+2 \mathrm{mg} \mathrm{L}^{-1}$ ANA apresentando média de 4 raízes/ explante (Figura 4). A maior quantidade de raízes nos explantes surge de uma combinação equilibrada de auxinas e citocininas, principalmente quando prevalece o efeito estimulante das primeiras (Caldas et al., 1998; George, 1993).

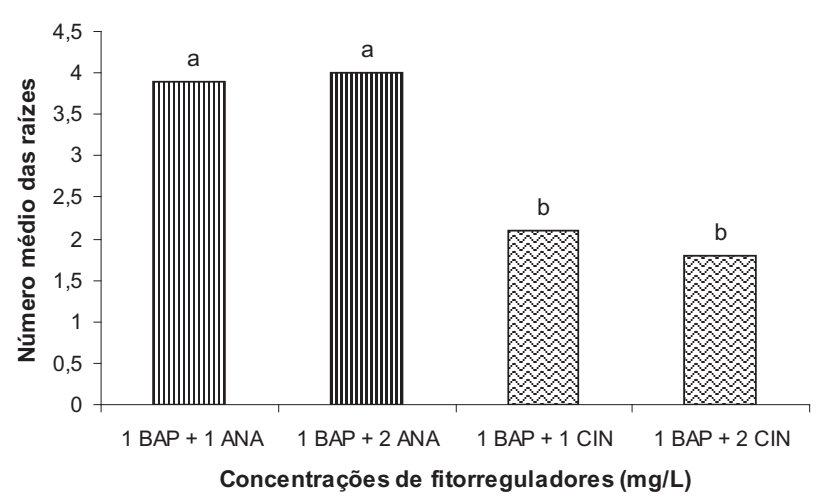

FIGURA 4: Efeito da adição de fitorreguladores no número médio das raízes de Etlingera elatior cv. Red Torch, ao longo de 90 dias de cultivo in vitro.

Tem sido demonstrado que um aspecto importante no enraizamento in vitro é a composição dos meios de multiplicação prévia a que foram submetidos os explantes (Assis \& Teixeira, 1998). Explantes oriundos de meios de multiplicação com mais citocininas, em geral necessitam de um balanço de reguladores que favoreça mais as auxinas do que as citocininas (Grattapaglia \& Machado, 1998).

0 comprimento médio das raízes também foi favorecido pelo mesmo tratamento que favoreceu 0 seu número (1 $\mathrm{mg} \mathrm{L}^{-1}$ BAP $+2 \mathrm{mg} \mathrm{L}^{-1}$ ANA) apresentando o dobro do comprimento médio dos explantes dos outros tratamentos após 90 dias de cultivo (Figura 5). Borthakur et al., (1999), trabalhando com a micropropagação Alpinia galanga, espécie de Zingiberaceae, suplementou o meio de cultura MS com diversas combinações ou isolados dos reguladores 
de crescimento BAP, ANA e CIN, e verificou um maior comprimento das raízes $(4,5 \mathrm{~cm})$ ao utilizar o meio isolado de $3 \mathrm{mg} \mathrm{L}^{-1}$ de $\mathrm{CIN}$.

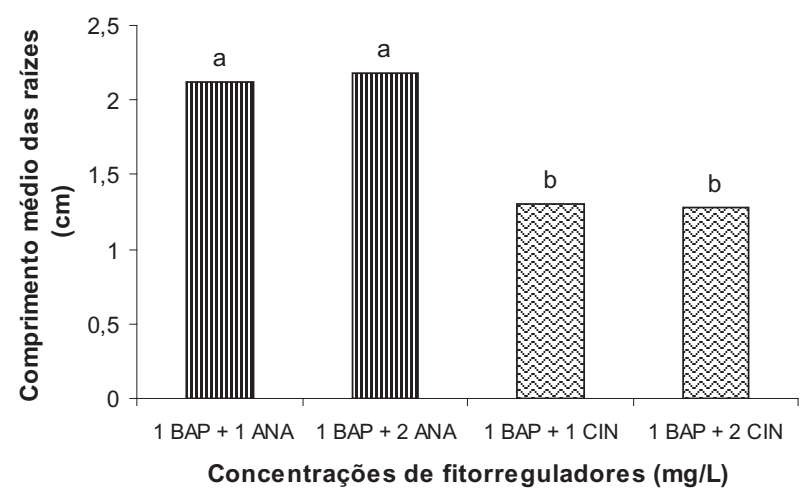

FIGURA 5: Efeito da adição de fitorreguladores no comprimento médio das raízes $(\mathrm{cm})$ de Etlingera elatior cv. Red Torch, ao longo de 90 dias de cultivo in vitro.

A maior taxa de multiplicação in vitro observada nesse trabalho, de 10,04 brotos após 90 dias, pode ser considerada um bom avanço para a micropropagação dessa espécie, sendo compatível com resultados obtidos com outras plantas da mesma família (Zingiberaceae) ou famílias relacionadas (Heliconiaceae, Musaceae, Costaceae).

A aclimatização das microplantas após 30 dias em telado apresentaram uma taxa de pegamento de $82 \%$, sendo que, após 60 dias, as mudas sobreviventes apresentavam-se desenvolvidas 0 bastante (cerca de $20 \mathrm{~cm}$ de comprimento) com sistema radicular abundante para serem transferidas para o campo.

\section{CONCLUSÕES}

1. É possível estabelecer plantas in vitro com a utilização de embriões isolados de sementes, de Etlingera elatior cv Red Torch cultivados em meio de cultura na presença de até $2 \mathrm{mg} \mathrm{L}^{-1}$ de BAP;

2. A germinação de embriões isolados é superior à germinação de sementes, sendo recomendada para iniciar culturas in vitro de Etlingera elatior cv. Red Torch;

3. A utilização do meio de cultura MS enriquecido com $1 \mathrm{mg} \mathrm{L}^{-1} \mathrm{BAP}+2 \mathrm{mg} \mathrm{L}^{-1} \mathrm{CIN}$, proporciona alta taxa de multiplicação na espécie Etlingera elatior cv. Red Torch, cultivada in vitro;

4. O maior número e comprimento médio de raízes, em plântulas de Etlingera elatior cv. Red Torch cultivadas in vitro são obtidos com o meio MS suplementado com $1 \mathrm{mg} \mathrm{L}^{-1} \mathrm{BAP}+2 \mathrm{mg} / \mathrm{L}^{-1} \mathrm{ANA}$;

\section{AGRADECIMENTOS}

À CAPES pela concessão da bolsa à primeira autora e à Sra. Lizete Monteiro, produtora de flores tropicais, pela doação de frutos de bastão do imperador para a retirada das sementes.

\section{REFERÊNCIAS BIBLIOGRÁFICAS}

ASSIS,T. F.; TEIXEIRA, S.L. Enraizamento de plantas lenhosas. In: TORRES, A. Carlos, CALDAS, L. S., $B U S O$, J. A. (Ed.). Cultura de tecidos e transformação genética de plantas. Brasília: EMBRAPA/CBAB. v.1, 1998, p.87-132.

BORTHAKUR, M.; HAZARIKA, J.; SINGH, R. S. A protocol for micropropagation of Alpinia galanga. Plant cell, tissue and orgam culture, v. 55, p. 231-233, 1999.

CALDAS, L. S.; HARIDASSAN, P.; FERREIRA, M. E. Meios nutritivos. In: TORRES, A. Carlos, CALDAS, L. S., $B U S O$, J. A. (Ed.). Cultura de tecidos e transformação genética de plantas. Brasília: EMBRAPA/CBAB. v.1, 1998, p.87-132.

CASTRO, C. E. F. Heliconia para exportação: aspectos técnicos da produção. Brasília: MAARA-SDRFRUPEX/ISPI. (FRUPEX. Publicações Técnicas, 16). 1995

CASTRO, C. E. F. Curso: Técnicas de cultivo de flores tropicais. 1998.

CHAGAS, A. J. da C. Floricultura tropical na zona da mata de Pernambuco. Recife, SEBRAE, 2000.24 p.

DUVAL, F. G. Cultura de embrião e anotomia do desenvolvimento de embrião zigótico de heliconia rostrata. 2004. CAPES-Banco de teses. Universidade de Brasília.

GEORGE, E. F., Plant propagation by tissue culture. The technology. Exegetics Limited., London. 1993. $574 p$. 
GRATTAPAGLIA, D.; MACHADO, M. $\quad$ A. MELLO, M. O.; AMARAL, A. F. C. MELO, M. Quantifying Micropropagação. In: TORRES, A. C., CALDAS, L. S., the micropropagation of Curcuma zedoaria Roscoe. BUSO, J. A. (Ed.). Cultura de tecidos e transformação genética de plantas. Brasilia: EMBRAPA/CBAB. v.1. 1998 p.183-260.

HU, C. Y.; FERREIRA, A. G. Cultura de embriões. In: TORRES, A. C.; CALDAS, L. S.; BUSO, J. A. (Ed.). Cultura de tecidos e transformação genética de plantas. Brasília: EMBRAPA/CBAB. v.1, 1998, p.261296.

HU, C. Y.; WANG, P. Embryo Culture: Technique and applications. In: EVANS, D. A.; SHARP, W. A.; AMIRATO, P. V. ed. Handbook of plant cell culture. New york: Macmillan, 1986. v.4, p. 43-96.

LAMAS, A. M. Floricultura tropical: Técnicas de cultivo. Recife: SEBRAE/PE, 2002. 88p.

LOC, N. H.; DUC, D. T.; KWON, T. H.; YANG, M. S. Micropropagation of Zedoary (Curcuma zedoaria Roscoe) - a valuable medicinal plant. Plant cell, tissue and organ culture, v. 81, p.119-122, 2005.

LOGES, V.; SOUZA, J. W. O.; PINHEIRO, P. G. L.; CASTRO, A. C. R. de; LIRA JUNIOR, M. A. Desenvolvimento de inflorescências de Etlingera elatior, Tapeinochilos ananasseae e Zingiber spectabilis. In: CONGRESSO BRASILEIRO DE FLORICULTURA E PLANTAS ORNAMENTAIS, 14. CONGRESSO BRASILEIRO DE CULTURA DE TECIDOS, 1. Lavras, 2003. Anais. Lavras: UFLA/ FAEPE, 2003. p. 395.

Scientia Agricola. v. 57, n. 4, p.703-707, 2000.

MURASHIGE., T.; SKOOG, F. A Revised Médium for Rapid Growth and Bioassays With Tabacco Tissue Culture. Physiologia Plantarum, v.15, p. 437-497, 1962.

RAGHAVAN, V. Embryo culture. Internantional Revision Cytology, n.11. 1980. p.209-240.

RODRIGUES, P. H. V. In vitro establishment of Heliconia rauliniana (Heliconiaceae). Scientia Agricola. v. 62, n. 1, 2005.

SHARMA, T. R.; SINGH, B. M. High-frequency in vitro multiplication of disease-free Zingiber officinalle Rosc.

Plant Cell, Report, v.17, p. 68-72, 1997.

TORRES, A. C., DUVAL, F. D.; RIBEIRO, D. G.; BARROS, A. F. F.; ARAGÃO, F. A. D. Efeito da sacarose, cinetina, isopentenil, adenina e zeatina no desenvolvimento de embriões de Heliconia rostrata in vitro. Horticultura Brasileira. v. 23, n.3, 2005.

WILLADINO, L.; CÂMARA, T. Cultura de tecidos vegetais: Cultivo in vitro de vegetais. Departamento de Química, Laboratório de Pesquisa Cultura de Tecidos Vegetais. 2005. Disponível em: <http://ufrpe.br/quimical culttec.htm>. Acesso em: 6 março 2006. 